Western University

Scholarship@Western

Department of English Publications

English Department

$3-2016$

For the Progress of "Faustus and Helen": Crane, Whitman, and the Metropolitan Progress Poem

Jeremy Colangelo

Department of English, jcolang2@uwo.ca

Follow this and additional works at: https://ir.lib.uwo.ca/englishpub

Part of the Literature in English, North America Commons, Modern Literature Commons, and the United States History Commons

Citation of this paper:

Colangelo, Jeremy, "For the Progress of "Faustus and Helen": Crane, Whitman, and the Metropolitan Progress Poem" (2016).

Department of English Publications. 143.

https://ir.lib.uwo.ca/englishpub/143 


\section{ResearchGate}

See discussions, stats, and author profiles for this publication at:

https://www.researchgate.net/publication/299526018

\section{For the Progress of "Faustus and Helen": Crane, Whitman, and the Metropolitan Progress Poem}

Article in Canadian Review of American Studies · March 2016 DOI: $10.3138 /$ cras.2015.003

READS

6

1 author:

Jeremy Colangelo

The University of Western ...

4 PUBLICATIONS O CITATIONS

SEE PROFILE 


\title{
For the Progress of
} "Faustus and Helen": Crane, Whitman, and the Metropolitan Progress Poem

\author{
Jeremy Colangelo
}

\begin{abstract}
This essay is meant to invigorate a critical discussion of the progress poem-a genre that, while prevalent in American literature, has been virtually ignored by critics and scholars. In lieu of tackling the genre in its entirety, a project too large for just one article, the author focuses the argument through the well-known alignment between Walt Whitman and Hart Crane on the subject of the modern city. It is through the progress poem genre that Crane and Whitman's peculiar place in metropolitan poetics can best be understood, and it is through their poetry that scholars can begin to approach the broader issue of the progress poem's place in American literature.
\end{abstract}

Keywords: progress poem, Hart Crane, Walt Whitman, modernity, city

Résumé : Cet article vise à soulever un débat critique au sujet de la poésie du progrès, un genre courant dans la littérature étatsunienne, mais pratiquement ignoré par les critiques et les commentateurs. Plutôt que d'aborder le genre dans son entièreté - un projet qui déborde du cadre d'un article - l'auteur resserre l'argumentation autour du parallèle bien connu entre Walt Whitman et Hart Crane concernant le traitement de la ville moderne. C'est la poésie du progrès en tant que genre qui permet le mieux de comprendre la place particulière qu'occupent ces deux auteurs dans la poésie métropolitaine, et c'est par leurs poèmes que les chercheurs peuvent aborder la question plus vaste de la place du poème sur le progrès dans la littérature étatsunienne.

Mots clés : poésie du progrès, Hart Crane, Walt Whitman, modernité, la ville 
[M]yself disintegrated, everyone disintegrated yet part of the scheme.

$$
\text { —Walt Whitman, "Crossing Brooklyn Ferry" }
$$

Seeing himself an atom in a shroud-

Man hears himself an engine in a cloud!

- Hart Crane, "The Bridge"

This article is meant, primarily, to jump-start a scholarly discussion of the progress poem, a sorely-neglected literary form that has flourished in Anglo-American literature for almost as long as that literature has existed. Given the size of this task, a complete survey and critique of the form is beyond the scope of a single article. Instead of attempting to be encyclopedic, I have sought to articulate the issue by means of what Pound might call a "luminous detail" - in this case, the idiosyncratic attitude Hart Crane and Walt Whitman had toward modern technology and the modern city. The Crane/Whitman relationship is my example precisely because of how well known it is, since that fact will underline the pervasiveness of the progress poem in American literature and the importance of increased scholarly attention to it. In order to make this argument, I will need not only to define the term "progress poem," but also to explain the peculiarities of its integration with American literature generally, and in particular its close affinity with the jeremiad. This more direct, surgical approach will hopefully lay the groundwork for future analysis of the form.

$* * *$

In a letter to Waldo Frank written in 1923, Hart Crane described the structure of his poem "For the Marriage of Faustus and Helen" as "a kind of fusion of our own time with the past," and said that "almost every symbol of current significance is matched by a correlative, suggested or actually stated, 'of ancient days.' . . . The street car device is the most concrete symbol I could find for the transition of the imagination from the quotidian details to the universal consideration of beauty. . ." (Letters 120). While Crane's aesthetic of synthesis has been oft-discussed in the critical analysis of this poem, I would like to draw attention, instead, to the latter line about the street car-a metaphor that is the vehicle (fittingly enough) of the "fusion" that Crane sought between the physical and the imaginary, the classical and the romantic. His use of this kind 
of metaphor is as clear a sign as any of Crane's debt to Walt Whitman. As John Timberman Newcomb describes, Whitman's poetry is almost unique among the verse produced in the nineteenthcentury United States, which had in general "expressed powerful antipathy toward the modernization transforming the nation," holding out "the industrialized city" as a symbol of this transformation (147); whereas, in Richard Haw's characterization, poems like "Passage to India" and "Song of the Exposition" show that Whitman "saw industrial progress and democracy in correlation. .." (15).

One way in which we can see the importance of this difference in Whitman's poetic engagement with modernity is by comparing him to Emerson, particularly in terms of how the two described crowds. As Larzer Ziff has argued, Emerson tended to see in crowds the devouring of individuality by a group identity, as for instance when he complained in his journal about a local politician, writing that "I hate numbers. He [the politician] cares for nothing but numbers \& persons. All the qualities of man, all his accomplishments, affections, enterprises except solely for the ticket he votes for, are nothing to this philosopher" (200). Ziff analyzes 184 this passage in terms of Emerson's dislike of using crowds qua crowds as subjects of literary works (585) - a preclusion from which Whitman never suffered. However, Ziff misses the importance of technology in Emerson's conception of crowds. For example, in "Nature" he remarks that "one needs only get into a coach and traverse the town, to turn the street into a puppet-show. The men, the women . . . are unrealized at once . . . and seen as apparent, not substantial beings" (21). The speed of the coach, which sends the outside world whizzing by too fast for observation, is also for Emerson an agent for the subsuming of the individual into the group. This speed, for Emerson, is also associated with the cityfor he sets the scene within "the town," as opposed to the forest or the countryside. By comparing the increasing speeds of rail travel to the relatively prosaic movement of a coach it is easy to see what effect modern technology would have on this issue. We can also see how Whitman's embrace of the crowd as a subject for poetry required a revised look at the individuating role of modern technology. If technology can allow a person to transcend both the lonely individual and the undifferentiated mass by creating a community, then it can be an agent of democracy. If not, not. 
Consider, then, Whitman's "Passage to India," where then-new technologies like the railroad and the telegraph allow "[t]he earth to be spann'd, connected by network / . . . the lands be welded together" (288) - we see a democratizing ethos, wherein modern technologies reverse the alienation brought on by the dispersal of humanity across the vast expanse of the globe (one can imagine what Whitman would have said about the Internet). For Whitman, it is technology that elevates the crowd beyond the limitations of mere "numbers." This ethos of course merges with Whitman's poetic tendency to try to "forge a sense of community by representing its diversity in the realm of one literature" (Oerlemans 709). The connection in these terms between Whitman and Crane has been pointed out before, in particular as it relates to Crane's "The Bridge" (Erkkila 288), but insofar as Crane's relationship with Whitman and their similar understandings of technological modernity relate to "Faustus and Helen," the discussion has been missing a key piece of context.

This context is the poetic genre known as the progress poem, or progress piece, ${ }^{1}$ a genre into which "Passage to India," "Crossing Brooklyn Ferry," "Faustus and Helen," and "The Bridge" all fall. A major obstacle to discussing the genre is the dearth of critical and scholarly discussion about it-an absence that is quite surprising given the large number of American progress poems. Making the task even harder is that what little published work there is on the genre focuses on poetry in England, mainly in the seventeenth and eighteenth centuries. ${ }^{2}$ It seems that, almost totally unbeknownst to scholars of American literature, there was a flowering of progress poetry covering several major writers, stretching from as far back as Freneau's "Rising Glory of America" all the way to more recent poets like Allen Ginsberg, whose "Howl" fits easily into the genre. ${ }^{3}$

As far as I have been able to tell, the most recent piece of largescale scholarship published on the genre is a PhD thesis completed in 1960 by John Richard Crider, The Seventeenth and Eighteenth Century Progress Pieces. The dissertation mostly concerns itself with listing and cataloguing examples of the form (it contains an appendix listing almost 190 examples, with John Trumbull's The Progress of Dullness being the only piece of American literature included) and 
at the present time is probably the most useful and authoritative source on the genre. In his survey, Crider divides the genre into "biographical" and "historical" progress poems, the difference lying in their subject matter. Both types describe the "progress" of some kind of figure-a person for "biographical" progress poems or an abstract concept for "historical" ones-as it changes over a period of time. Vitally, a progress poem is not merely a poem about progress, but rather a poem which uses progress as a metaphor to organize its discussion of a more complex topic (Crider i-ii). The historical progress poem, in the American context, seems to have taken the firmest root, and it is this mode that I would fit the Whitman and Crane poems under discussion. As Crider describes, the historical progress poem "typically takes as its object the historical manifestations of a human quality or activity and assumes the unity and continuity of this universal throughout its particular occurrences" (113), with the progress of the concept following the metaphorical logic of a "journey" (i). In general, poems in this mode tend to formulate an idea as some kind of abstract, unified entity (often by anthropomorphizing it) and to describe its various manifestations over a certain period of time. And it is precisely this extension through time that makes authors of progress poems, including Whitman and Crane, so stylistically different from poets like Pound, who use as the base unit of the poetic work a singular "image" that remains relatively static within the narrow snapshot we are given. True, as Pound demonstrates, one can abandon the unities at the base of the progress poem and still produce extended poetical works, but these works, in their very style, resist the poetic tropes which constitute the genre. Small wonder, then, that at least one critic has said that Crane's "aesthetic suggests a notion of poetic language completely opposite of Pound's" (Dean 84).

While Crider, echoing the earlier work on the genre by R.H. Griffith, dismisses the historical progress poem as a "fad" (260), its importance in American poetry-from the "rising glory" poems on-would suggest otherwise. The explanation for this disagreement lies in the historical progress piece's similarity to what Scavan Bercovitch identified as the tradition of the jeremiad in American literature and culture. As he writes, the jeremiad "was a ritual designed to join social criticism to spiritual renewal, public to private identity, the shifting 'signs of the times' to certain traditional metaphors, themes, and symbols" (xi). Like the historical progress poem, the jeremiad relies on the creation of an abstract 
idea that can be given a quasi-concrete form (the "metaphors, themes, and symbols") and the stratification through time of its various manifestations. The traditional Biblical jeremiad, as Bercovitch describes, begins with "a precedent from scripture that sets out the communal norms; then, [presents] a series of condemnations that details the actual state of the community ... and finally [ends with] a prophetic vision that unveils the promises, [and] announces good things to come. .." (16). The two literary modes can be mapped onto each other quite easily: the "communal norms" become an abstract notion or activity the progress of which is the subject of the poem, the "condemnations" of the state of that norm in the present locates the notion in a temporal progress, and the utopian future that the jeremiad concludes with continues that progress further. Thus the jeremiad, like the progress poem, is a genre founded on temporality.

I do not mean to say that all American jeremiads are progress pieces, or that all progress pieces are jeremiads, but rather that the commensurability of the two forms, in concert with the jeremiad's prominence in American culture, is a very likely reason why the historical progress poem has become so prevalent within American literature. In fact, the American jeremiad's progressive disassociation from overt religiosity, focusing instead on other abstract concepts or "errands" such as manifest destiny, likely brought the two modes closer together, and further distinguished the American progress poem from its British counterpart. Though many progress pieces-like Bunyan's Pilgrim's Progress-made religion their central subject, the historical progress poem could take essentially any idea as its theme so long as that idea could be described in terms of a temporal progression. So, for example, when Whitman "attempted to sketch in Leaves of Grass the ideal that his country had not yet achieved" (Miller 47), he can be seen as performing a synthesis of the jeremiad with the progress poem that achieves what neither could on their own. Whereas the traditional jeremiad required the pre-existence of a norm that the culture had deviated from, or some goal or "errand" that had been abandoned, and is in that sense essentially regressive, Whitman's work posited a possible future which was unlike anything that had existed in the past but which had its seeds in the country's history. The continentspanning affirmation of a poem like "Song of Myself" is nothing like what one would find the Puritans writing, but it does allow for the possibility that what has existed in the past creates the 
conditions for what the poet sees in the present and wishes for the future. The genre therefore allows Whitman to borrow a version of the jeremiad form without having to rely on the pattern of condemnation and religious indignation which is the jeremiad's basis. The progress poem thus created within the jeremiad an expanded place for optimism. As such, when the two modes are coincident (as in Whitman), one vision cannot be allowed to blot out the other.

These differences in temporality are vital for understanding a poem like "Passage to India." It is a poem obsessed with time, as established in the first stanza which explicitly positions the technological developments of the day in chronological and historical terms. Yet the second stanza introduces a turn: though it invokes "the infinite greatness of the past," it does so in order to call not for a return to it (as in a jeremiad) but rather for greater movement forward. As the next lines observe, "what is the present after all but a growth out of the past? / (As a projectile form'd, impell'd ... still keeps on / So the present . . . impell'd by the past)" (288). The non-recurrence of the past is central to the logic of the poem, which figures the opening up of the eponymous "passage to India" (through America, by rail, and through the Suez Canal) in terms of a preordained synthesis of humanity that, though attributed to the intention of God, had yet to occur in history. This ultimate cosmic synthesis, in which God takes the role of the "motive of the stars . . . / That, circling, move in order, safe, harmonious / Athwart the shapeless vastlessness of space" (293), locates in the past both the chaos of an uncontrolled universe and the conditions of a future harmony. Thus, one may look back, but one should never go back. Finally, Whitman sees this abstract teleology enacted in the quotidian matters of modern technology. Thus, the poem does not merely celebrate modernity as the climax of history, but instead lauds it for containing the seeds of a better future in the same way that the present was "impell' $\mathrm{d}$ " by the past. This is not how a jeremiad usually works, but it is very much the structure of a progress poem. Thus, Whitman's use of the form not only sets him apart from contemporaries like Emerson, but also aligns him with Crane, who likewise uses the progress poem to produce an image of modernity that is ultimately optimistic. The past is not as precious for Whitman and Crane as it is for their contemporaries; it is only through a form that points into the future that they can find the synthesis they seek. 
That Crane's fellow modernists, like T.S. Eliot and Allen Tate, would balk at this kind of writing should make a good deal of sense-one could call "The Waste Land" and "Ode to the Confederate Dead" a lot of things, but "optimistic" is not one of them. But the affirmation that results from Whitman's synthesis of the jeremiad with the progress poem serves also to help articulate the place that the advancement of technology and the industrialized city have in his overall poetic vision, and how Crane's poetry fits into the pattern that Whitman set. Take, for example, a poem like Whitman's "Crossing Brooklyn Ferry," which provides an epigram for this essay. Like "Passage to India," it figures new technologies as tools for bridging the spatial divides that exist normally between people, with the technology in this case being the eponymous ferry. However, the development we see in this poem is not a simple movement from alienation to community on the back of modernity, but rather a far more complex development, in which everyone is "disintegrated, yet part of the scheme" (116). Consider two of the poem's opening lines: "on the ferry-boats the hundreds and hundreds that cross, returning home, are more curious to me than you suppose, / And you that shall cross from shore to shore years hence are more to me, and more in my meditations, than you might suppose" (116). A transfer is here, from the first line to the second, between the figuration of the crowd as an undifferentiated mass (one thinks of Eliot: "a crowd flowed over London Bridge, so many, / . . each man fixed his eyes before his feet / Flowed up the hill and down King William Street. . ." [lines 62-6, emphasis added]) to the creation of a "disintegrated" "you." Though the word "you" appears a few times in the earlier lines of the poem, in those instances it is always directed at a feature of the environment (the water or the sky). The "you" of the second line I quoted from "Brooklyn Ferry" is the first one that Whitman affixes to a person-an idealized future reader, or a future rider of the ferry. The singular "you" is a necessity in Whitman's poem if one is to distinguish the homogenous mass from something that we might call "community." To be disintegrated, that is, to be severed from one's surroundings, seems like the kind of existence occupied by the anonymous men on Eliot's London Bridge, who stare only at their shoes.

Whitman, though, sees a way out of this lonesome anonymitythrough a community of recognition as affected by the shared use of new technology. As he writes later in the poem: "consider, you 
who peruse me, whether I may not in unknown ways be looking upon you" (119). The "you" here is very important, as it serves the function of recognition-that is, the manner in which one achieves the seemingly contradictory, anti-Emersonian state of being "disintegrated, yet part of the scheme." The shared experience of riding the Brooklyn ferry (or, perhaps, reading "Brooklyn Ferry") affords a moment of recognition, and through that, community, just as the fourth wall-breaking "you" acts out this recognition within the diction of the poem itself. The ferry-goers of Whitman's poem thus progress from mass to community by avoiding the trap of the steps immediately before them and recognizing the shared experience offered by the journey from one side of the river to the other. It is less important, then, that the people cross the river, than that they do so together, thereby changing from the thoughtless multitudes that Emerson criticized into a community.

The idealization of the ferry is important not only for placing "Brooklyn Ferry" in the history of the progress poem, but also for figuring its relationship with "The Bridge" and "Faustus and Helen." "Brooklyn Ferry" is a progress poem because of its projection into the future of a continued community brought on by the abstract notion of community-through-mutual-recognition, given concrete form by the ferry. That the emphasis is on an abstract notion represented by the ferry, and not on the ferry itself, must be understood if we are to read "The Bridge" as an inheritor of the poem, if only because the construction of the Brooklyn Bridge essentially eliminated the ferry's centrality in the life of Brooklyn's residents. ${ }^{4}$ In fact, as Haw points out, despite Whitman's frequent association with the Brooklyn Bridge-essentially an historical accident-he wrote almost nothing about it (6-7). But "Brooklyn Ferry" and "Passage to India" echo through "The Bridge" through the generic structure of a progress poem, and through their shared subject of the "progress" of a synthesis brought on by the advancement of modernity. Looked at in this way, the construction of the Brooklyn Bridge, though bringing about the end of the ferry, is less the death-knell for a community than the creative impetus for an even larger community, not only through the greater ease of connection between the two sides of the river and the expansion of the shared experience of the crossing, but also through the conspicuous place that the bridge holds in the Brooklyn skyline. 
Turning now to "The Brooklyn Bridge" - the opening section of Crane's "The Bridge"-we can see the continuation of the kind of theme we saw in "Brooklyn Ferry" and "Passage to India":

I think of cinemas, panoramic sleights

With multitudes bent toward some flashing scene

Never disclosed, but hastened to again,

Foretold to other eyes on the same screen;

And thee, across the harbour, silver-paced

... Implicitly thy freedom staying thee! (43)

A progression like the one we saw in "Brooklyn Ferry" is present here. In the first two lines, we have a mass of disconnected people, present in the now-familiar image of an audience in a movie theatre, robbed in their "multitudes" of individuality. But a kind of community is here, as shown in the second two lines in which the image on the film, though "never disclosed," is "foretold to other eyes on the same screen." Thus, as with the ferry passengers, the shared experience of watching the film and the shared presence of the other "eyes" in the theatre create the possibility of a community within the mass. The poem then transitions to the harbour and a moment of recognition across it, ending the stanza about the cinema not with a period, but with a semicolon, including both stanzas in the same thought. This includes the crossing of the span in a pattern of community-building recognition that is, as with Whitman, mediated visually.

That there is a lot of Whitman in "The Bridge," and Crane's poetry in general, has been noticed by many scholars already-but their mutual use of the progress poem genre, and that genre's presence in their attitudes toward technology, industrialisation, and modernity, has, as far as I have been able to tell, never been remarked upon in any published source. This set of relations extends also to "Faustus and Helen," as is best demonstrated through an analysis of the poem's debt to Walter Pater, established by John Irwin (326). Specifically, Irwin refers to a passage in The Renaissance in which Pater discusses the conflict, and eventual synthesis, between two seemingly opposite aesthetic modes, which Peter identifies with Helen and Faust respectively: "Goethe illustrates a union of the Romantic spirit, in its adventure, its variety, its profound 
subjectivity of soul, with Hellenism, in its transparency, its rationality, its desire for beauty-that marriage of Faust and Helena, of which the art of the nineteenth century is the child. . ." (189, emphasis added). This kind of fusion maps well onto Crane's own stated aesthetic goals, such as in a letter to Gorham Munson where he wrote that he was attempting to perform a "graduation from the quotidian to the abstract" (Letters 96). We can see, too, elements of "The Bridge" in The Renaissance-as in Pater's earlier analysis of the two parts of Faust, where he discusses the semi-oppositional relationship between art and science (93-4). But the importance of Crane's connection to Pater insofar as "Faustus and Helen" is concerned lies in Crane's adoption of Pater's idea of aesthetic synthesis between classicism and romanticism.

Let us look then at these lines from the poem's first section: “. . suppose some evening I forgot / The fare and transfer, yet got by that way / . . I might find your eyes across an aisle" (I.19-22). The similarity between the way that the poem's speaker described seeing Helen across an aisle and the narrator's description in the opening section of "The Bridge" is striking, but predictable if we understand both sections as being inheritors of the poetic logic that Whitman followed in "Brooklyn Ferry" and "Passage to India." In this moment of recognition, we can see Crane's aesthetic of synthesis being transposed into the logic of the progress poem. It is not merely Faustus and Helen and the ideas they represent which are having their progressions through time represented in the poem, but rather the ongoing, impossible marriage of the two. A few lines earlier, Crane writes: "there is the world dimensional for / those untwisted by the love of things / irreconcilable" (I. 16-18). I would like to single out here the word "dimensional." The term refers primarily to spatiality, conjuring a notion of the extension of the "world" in physical space. That this line leads immediately to a Whitmanesque recognition of one subject by another across a physical span makes the term doubly important, especially given the description of a cityscape that we encounter in the lines just before the interjection:

Numbers, rebuffed by asphalt, crowd

The margins of the day, accent the curbs,

Convoying drivers dawns on every corner

To druggist, barber and tobacconist (I. 9-12). 
Present here is an Emersonian en masse-ing of the "disintegrated" people of the city, where the people become "numbers" that pound the street. They are individuated through their mode of employment- "druggist, barber and tobacconist"-following the invocation of a mode of transportation ("drivers"), much as in "Crossing Brooklyn Ferry." The poem provides a moment of recognition only after the interlude, holding forth the possibility that the clash of "things / irreconcilable" could leave someone "untwisted," that a moment of recognition is made possible.

And yet I do not think that there is ever a completion of this synthesis. If we take the poem's last two lines-"the imagination spans beyond despair / Outpacing bargain, vocable and prayer" (III. 47-8) - what we encounter is somewhat like the vision of the artist's creativity we see in William Carlos Williams's Spring and All, where the "imagination" acts as an engine of creative synthesis that makes poetry possible. But Crane's "imagination" extends beyond the physical forms that it might take, the "bargain, vocable and prayer" of the person doing the imagining. Rather, it is the name we could, in the mould of Pater, give to the offspring of the marriage of Faust and Helen, that abstract idea that we see progressing through time which permits "Faustus and Helen" to lay claim to the status of a progress poem. If this "imagination," as Crane's poem suggests, is the result of the mutual recognition lying at the basis of community formation in Whitman's work, then we can conclude that the progressing notion this poem describes is nothing less than the very basis of all artistic creation insofar as Crane conceived it. ${ }^{5}$ However, this reading also puts the aesthetic relationship between Crane and Eliot (as Crane appears to have expressed it) into new relief, particularly if one looks at the stanza just a few lines above the final couplet:

A goose, tobacco and cologne -

Three winged and gold-shod prophecies of heaven,

The lavish heart shall always have to leaven

And spread with bells and voices, and atone

The abating shadows of our conscript dust. (III. 31-5)

If we avoid being distracted by the "winged and gold-shod prophecies of heaven" for just a moment, we can see this stanza's many connections to the other sections of the poem. The wings of the "prophecies" and the goose could refer to the earlier section 
about the aerial dogfight-living, flapping wings here substituted to the mechanical fixed wings of a biplane-and could also stand in for the "cupids" of II. 8, while the tobacco recalls the tobacconist we saw in the section of Part I, quoted above. Meanwhile, the "conscript dust" could easily be an allusion to the "handful of dust" in "The Waste Land." But then what of the "bells and voices"? Among other things, ${ }^{6}$ they look forward to the "vocable and prayer" of the final two lines.

The internal references made in the above-quoted stanza, along with the final couplet's claim to have brought the poem "beyond despair," are all best understood within the framework of an historical progress poem. One can look at these final stanzas as an internal recycling akin to the "Circe" episode of Joyce's Ulysseswhere shades of old images and ideas crop back up and are recomposed in a new context. It is precisely the historical progress poem's reliance on the chronological progression of abstract ideas through the medium of one or more concrete objects that allows Crane to perform an act of Joycean recombination while also producing a kind of poetic movement. Crane is able, here, to move "from the quotidian to the abstract" because it was always the abstract which lay at the heart of the poem's structure. If "Faustus and Helen" is indeed not so much about the two characters but about their marriage, then what we see is both an enactment of and a playing with the progress poem's usual trope of investing concrete objects with symbolic value so to chart those symbols' movement through history. But since this value is symbolic only, they can be detached from their original meanings, abandoned for several lines and brought back into the poem in a new context, or even made to proliferate with several objects standing in for the symbolic "imagination" that is both the goal and the offspring of the marriage that the poem marks.

We can therefore take Margaret Dickie's observation that, with Crane's decision to compose the "Atlantis" section first, "The Bridge" began "at the end, where Poe thought all works of art should begin. .." (47) and apply it, in a less literal way, to "Faustus and Helen." The poem, in fact, begins in the abstract-in exactly the mental space that Crane would have it finish. Only in its first lines, where "the mind" becomes "divided by accepted multitudes" (I. 1-3) and so unable to achieve the recognition that, as the poem indicates, is the epistemological basis for the creation of art, 
does the invocation of a "quotidian" world become necessary. The "mind," after all, only "at times" becomes divided (I. 1), which begs the question of what kind of mental state prevails when this division is subdued. The "marriage" of these internal warring states, of Faust and Helen, is achieved via the medium of these quotidian objects, which as the poem progresses are freely discarded and recombined as they become unnecessary.

It is through synthesis, not opposition, that the "imagination" necessary for the creation of art takes place. The result-by turns an opening up and a supressing of discordant voices, destabilizing the usual structure of an epic (Gabriel 7)—invests the poem with the kind of internal contradictions that Whitman would likely have appreciated. Just as, in "The Bridge," the "cables" of the Brooklyn Bridge "breathe the North Atlantic still" (43) only so that, in the next section, the "whiteness before the tides can wrest away / The world I bring" (47), so too is any synthesis at best momentary: the ferry ride that Whitman mythologizes can only last so long as the river is wide, and so, ironically, the duration of a shared experience, of a community, is bound up with the vastness of the gap traversed. Perhaps, then, Whitman's call to Columbus in "Passage to India" — "ah Genoese thy dream! thy dream!" (289)— can be given a new layer of tragedy: the arrival of Columbus failed to bring the continents together, and so crossing the river is the best that can be had.

Here again we have Emerson's "numbers," people traversing in a mass, nameless, stripped of their individuality, failing to attain the community of recognition that Whitman called for. But look, also, at the sounds at play in this passage: the "serenade" of the 
escalator's hum, the "gongs" of the arms-human and mechanicaland beyond that the implication of the continuous patter of raindrops landing on umbrellas. Though Crane denies these subwaygoers a community of sight, of one person spotting another across the span of the river, there is, instead, a community of sound, in the noises of the city (perhaps even more inescapable than the sights). We therefore see present in this stanza a mix: on the one hand an effect like what Warner Berthoff calls the rendering through "the hectic glamour and oppressiveness of modern city life the apocalypse of the First World War. .." (51), with this "apocalypse" registered in the inescapable alienation of the modern city; on the other, by the very means through which this alienation comes about, the creation of the mechanisms by which the divisions of the world can be overcome. Thus, if we are going to borrow Berthoff's term, the modern city in Crane's imagination is an apocalypse in two senses of the word: first in the colloquial sense, where it is roughly synonymous with "the end of the world," and second in the sense of it

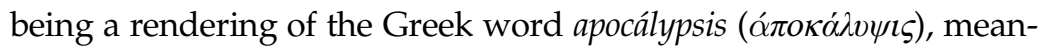
ing a "discovery" or "revelation."

The dual "apocalyptic" natures of modernity as envisioned by

196 Crane cannot be seen any better than in his description of an aerial dogfight in the opening section of Part III of "Faustus and Helen." Consider the position of a pilot of a biplane in the First World Warheld aloft, flying like a "winged and gold-shod prophec[y] of heaven," but only in a frail and somewhat rickety contraption, only a decade on from the Wright Brothers' flight in $1903^{7}$ (the earliest mass-made biplanes were little more than some canvas, metal tubing, and an engine). Throw on top of all this the fact that these pilots were flying over a battlefield, being shot at by other planes and by artillery, and Crane's "religious gunman!" remark (III. 6) makes a great deal of sense- to fly a fighter plane in the middle of the First World War was practically suicidal. Yet it is in this position of precarious flight, where the ability to leave the ground comes at the cost of exposing one's self to incredible danger, that these machines created the potential for recognition. Consider, in the opening stanzas of part III, the frequency of the collective first person pronouns "we" and "us": "let us unbind our throats of fear and pity // We even, / Who drove speediest destruction," and later, "we know, eternal gunmen, our flesh remembers" (III. 10-2; 19, emphasis added). As the pronouns register, even in this dangerous place, there is a chance of recognition, of a shared experience which could form the seed of a 
community. Though between each pilot is the body of the aircraft and the gap of open sky, once again the capacity to see, to make contact visually, invests the moment with a chance to recognize the presence of another consciousness. If the pronouns of the section are any indication, there is indeed a community present here, a "we" that can exist at least conceptually, and briefly, amidst the combat. Thus we have, in a moment of destruction, also a moment of revelation: an apocalypse in both senses of the term. ${ }^{8}$

The airplane battle, like the eponymous marriage of Faust and Helen, is, in effect, an act of creation brought on by a synthesis of opposing forces-be they the romantic and classical aesthetic modes, or soldiers in the stewing pot of war. Through the logic of the progress poem, inherited from Whitman, Crane is able to bring these disconnected images together so as to create not only "Faustus and Helen" but also the seeds of the narrative he would pursue in "The Bridge." As William Carlos Williams wrote in his essay on Columbus in In the American Grain, Columbus "heroically, but pitifully ... strove to fasten to himself that enormous world, that presently crushed him among its multiple small disguises" (10). Of course, the apotheosis of Columbus is simply unsustainable given the historical reality of his life- the onset of Europe's translatio imperii through the Americas, which brought with it centuries of slavery and of genocide for the people already there. One ought never to forget that the transcontinual railway lauded by Whitman in "Passage to India" was built as an expression of Manifest Destiny, along with all the death and misery that it implies. Yet, within these poems, it is the idea of $a$ "Columbus" - a force or figure of synthesis-that prevails. For the historical progress poem, the material objects to which the abstractions are affixed are precisely the least important aspects of the progression. The mistake would be to pretend that the "Columbus" that they honour denotes the person who actually existed, rather than a cultural myth. Let us then return to the line quoted above from Williams's essay. Once more we see Columbus as a central node of synthesis, this time among the vast "disguises" of a continent that remained quite mysterious to him. Columbus, then, is the "bridge," or the "ferry," or the "telegraph wire": the Columbian myth that Whitman et al. carry with them, and on which Crane's progress pieces stand, is that of the creation of a possibility for recognition, which for Crane is exactly that which lies at the basis of artistic creation. Thus, Crane is able to offer a vision of modernity in which the numbered 
masses of people walking through the city may, if given the chance, look up from their shoes and recognize the shared consciousness of the people around them. Through this possibility the structures of modernity, the cities and airplanes and technology, are able to exist without enforcing alienation on the people ensnared within them, and it is through the structures of the progress poem that Crane is able to communicate this capacity for recognition, all while using the same set of signifiers as those poets who would instead reject modernity and toss it out the window.

\section{Acknowledgments}

Prior to writing this essay I was privileged to read a chapter on the American progress poem in an in-progress book by Dr. Stephen Adams ("The Progress Poem in America: A Long View"), which proved to be highly useful, and made a strong mark on my argument. I would like to thank Dr. Adams for his assistance. A portion of this article was presented at the 2015 conference of the Northeast Modern Language Association (NeMLA) in Toronto, Canada.

Jeremy Colangelo is a PhD candidate in English at the University of Western Ontario. His work has also appeared in the James Joyce Quarterly and Joyce Studies Annual.

\section{Notes}

1 Within the critical discourse on the genre (such as it is), both phrases — "progress piece" and "progress poem" —are used fairly regularly, and refer to works with more-or-less the same generic conventions. My use of the latter throughout this essay stems from the fact that most of the works that I discuss here are poems, and it seemed prudent to err on the side of the narrower category.

2 The most recent published academic work that I could find which talked about the progress poem was an article in Women's Writing from 2005 about the eighteenth-century English poet Anna Barbauld, written by William Levine. Database searches for the term "progress poem" turn up almost nothing, and even less about poets from outside England.

3 Other focuses for research on the American progress piece could include (in no particular order) utopian fictions such as Edward Bellamy's Looking Backward, works deriving from the 1893 Chicago World's 
Fair, works in the early socialist and anarchist press, and the works of writers such as Willa Cather, Ernest Poole, and Carl Sandburg. That this list points to a very large and idiosyncratic yet-to-be-written work on the genre is precisely why I have confined my argument to a more narrow and focused approach for the time being.

4 The particular ferry that Whitman describes, the Fulton Ferry, stayed open for a short time after the bridge was completed, but was forced to close down in 1924—several years before "The Bridge" was published. In 2006 it reopened, but mostly as a tourist attraction.

5 This conclusion would be in line with Joseph Riddel's reading that "the creative act itself is the true subject of [Crane's] poems, the life of the poet-quester-visionary-lover-seeker whose role is as futile, and as necessary to himself as Sisyphus'" (478).

6 This line could also be an allusion to "The Waste Land": "And upside down in air were towers / Tolling reminiscent bells, that kept the hours / And voices singing out of empty cisterns and exhaused wells" (382-4).

7 Significantly, this flight appears in the "Cape Hatteras" section of "The Bridge," which begins with an address to Whitman.

8 As M.D. Uroff points out, Crane frequently uses violent metaphors to indicate instances of creativity - a trope that he borrows from the Romantics, but which he also makes his own (201). That this pattern is being repeated in the scene under discussion here goes without saying.

\section{Works Cited}

Bellamy, Edward. Looking Backward. New York: Dover Books, 1996.

Bercovitch, Scavan. The American Jeremiad. Madison: U of Wisconsin P, 1978.

Berthoff, Warner. Hart Crane: A Re-Introduction. Minneapolis: U of Minnesota P, 1989.

Bunyan, John. The Pilgrim's Process. Ed. W.R. Owens. Oxford: Oxford UP, 2003.

Crane, Hart. "The Bridge." The Complete Poems of Hart Crane: The

Centennial Edition. Ed. Marc Simon. New York: Liveright, 2001. 41-108.

Crane, Hart. "For the Marriage of Faustus and Helen." The Complete Poems of Hart Crane: The Centennial Edition. Ed. Marc Simon. New York: Liveright, 2001. 26-8. 
Crane, Hart. The Letters of Hart Crane, 1916-1932. Ed. Brom Weber.

Berkeley: U of California P, 1952.

Crider, John Richard. The Seventeenth-and-Eighteenth-Century Progress

Pieces. Phd diss., Rice U, 1960.

Dean, Tim. "Hart Crane's Poetics of Privacy." American Literary History 8.1 (1996): 83-109. <http://dx.doi.org/10.1093/alh/8.1.83>.

Dickie, Margaret. On the Modernist Long Poem. Iowa City: U of Iowa P, 1986.

Eliot, T.S. “The Waste Land." Collected Poems: 1909-1962. London: Faber \& Faber, 2002. 51-76.

Emerson, Ralph Waldo. Emerson in his Journals. Ed. Joel Porte. Cambridge: Belknap, 1982.

Emerson, Ralph Waldo. "Nature." Nature and Other Essays. New York: Dover, 2009. 1-34.

Erkkila, Betsy. Whitman the Political Poet. New York: Oxford UP, 1989.

Freneau, Philip. "The Rising Glory of America." The Poems of Philip Freneau: Written Chiefly During the Late War. London: J.R. Smith, 1861. 37-51.

Gabriel, Daniel. Hart Crane and the Modernist Epic: Canon and Genre Formation in Crane, Pound, Eliot, and Williams. New York: Palgrave Macmillan, 2007.

200 Ginsberg, Allen. "Howl." Howl and Other Poems. San Francisco: City Lights Books, 1959. 9-26.

Griffith, R.H. "The Progress Pieces of the Eighteenth Century." Texas Review 5 (1920): 218-223.

Haw, Richard. "American History/American Memory: Reevaluating Walt Whitman's Relationship with The Brooklyn Bridge." Journal of American Studies 38.1 (2004): 1-22. <http:/ / dx.doi.org/10.1017/ S0021875804007881>.

Irwin, John. Hart Crane's Poetry: "Apollinaire Lived in Paris, I Lived in Cleveland, Ohio." Baltimore: Johns Hopkins UP, 2011.

Joyce, James. Ulysses. Ed. Hans Walter Gabler. New York: Vintage, 1986.

Levine, William. "The Eighteenth-Century Jeremiad and Progress-Piece Traditions in Anna Barbauld's 'Eighteen Hundred and Eleven.'" Women's Writing: The Elizabethan to Victorian Period 12.2 (2005): 177-186. <http:/ / dx.doi.org/10.1080/09699080500200344>.

Miller, James E. The American Quest for a Supreme Fiction: Whitman's Legacy in the Personal Epic. Chicago: U of Chicago P, 1979.

Newcomb, John Timberman. How Did Poetry Survive?: The Making of Modern American Verse. Urbana: U of Illinois P, 2012. 
Oerlemans, Onno. "Whitman and the Erotics of Lyric." American Literature 65.4 (1993): 703-30. <http://dx.doi.org/10.2307/2927289>.

Pater, Walter. The Renaissance. New York: Modern Library, 1919.

Riddel, Joseph. "Hart Crane's Poetics of Failure." ELH 33.4 (1966): 473-96. <http://dx.doi.org/10.2307/2872203>.

Tate, Allen. "Ode to the Confederate Dead." Collected Poems, 1919-1976.

New York: Farrar, Straus, Giroux, 2007. 20-23.

Trumbull, John. The Progress of Dullness, or The Rare Adventures of Tom Brainless. Carlisle: George Kline, 1797.

Uroff, M.D. "The Imagery of Violence in Hart Crane's Poetry." American Literature 43.2 (1971): 200-16. <http:/ / dx.doi.org/10.2307/2924237>.

Whitman, Walt. "Crossing Brooklyn Ferry." Complete Poetry and Selected Prose. Ed. James E. Miller, Jr. Boston: Houghton Mifflin, 1959. 116-20.

Whitman, Walt. "Passage to India." Complete Poetry and Selected Prose. Ed. James E. Miller, Jr. Boston: Houghton Mifflin, 1959. 288-94.

Whitman, Walt. "Song of the Exposition." Complete Poetry and Selected Prose. Ed. James E. Miller, Jr. Boston: Houghton Mifflin, 1959. 143-50.

Whitman, Walt. "Song of Myself." Complete Poetry and Selected Prose. Ed. James E. Miller, Jr. Boston: Houghton Mifflin, 1959. 25-68.

Williams, William Carlos. In the American Grain. New York: New

Directions, 1956.

Williams, William Carlos. "Spring and All." Imaginations. Ed. Webster Schott. New York: New Directions, 1971. 85-154.

Ziff, Larzer. "Whitman and the Crowd." Critical Inquiry 10.4 (1984): 579_ 91. <http://dx.doi.org/10.1086/448265>. 